\title{
Condicionamento Alimentar de Alevinos de Trairão (Hoplias cf. lacerdae)
}

\author{
Ronald Kennedy Luz¹, Ana Lúcia Salaro², Eduardo Ferri Souto ${ }^{3}$, Walter Yoshizo Okano, \\ Renato Ribeiro de Lima 5
}

RESUMO - Este experimento foi conduzido com o objetivo de avaliar o condicionamento alimentar de alevinos de trairão (Hoplias cf. lacerdae). Foram utilizados seis aquários com capacidade para 20 litros cada, dotados de sistema artificial de aeração, temperatura controlada $\left(27 \pm 0,5^{\circ} \mathrm{C}\right)$, cobertos com lona plástica preta, mantendo o ambiente interno escuro todo o tempo (0L:24E), sendo descobertos apenas para os manejos diários. Alevinos de 2,9 $\pm 0,2 \mathrm{~cm}$ de comprimento foram estocados a uma densidade de 4 animais/L e submetidos aos seguintes tratamentos: aceitação direta de dietas artificiais e condicionamento alimentar por meio da substituição da ração semi-úmida por ração seca. Ao final do experimento, foram obtidas taxas médias de sobrevivência de 27,50 e 96,66\% para o primeiro tratamento e segundo tratamentos, respectivamente, evidenciando que o condicionamento alimentar é um manejo eficiente na produção e sobrevivência de alevinos de trairão.

Palavras-chave: condicionamento alimentar, dietas artificiais, Hoplias cf. lacerdae, trairão

\section{Training Strategies Trairao Fingerlings (Hoplias cf. lacerdae)}

\begin{abstract}
An evaluation of training strategies in fingerlings of trairao was carried out. The experimental design included six $20 \mathrm{~L}$ tanks with artificial aeration, controlled temperature variation $\left(27 \pm 0.5^{\circ} \mathrm{C}\right)$, and continuously darkened (0L:24D), except during daily management. Fingerlings with $2.9 \pm 0.2 \mathrm{~cm}$ long were kept at a 4 specimens $/ \mathrm{L}$ and they were allotted to the following treatments: the first was direct offering of artificial diet and the second involved training strategies by means of the replacement of semi humid food for dry food. At the end of the experiment, average survival rates were 27.5 and $96.66 \%$ for the first and second treatments, respectively, demonstrating that feeding conditioning is an efficient management in production and survival of Hoplias cf. lacerdae fingerlings.
\end{abstract}

Key Words: training strategies, dry pellets, Hoplias lacerdae, trairao

\section{Introdução}

O trairão (Hoplias cf. lacerdae), espécie carnívora, apresenta carne de excelente qualidade, podendo ser comparada com a de muitos peixes nobres brasileiros, tendo grande aceitação por parte da população; além disso, apresenta características desejáveis para a pesca esportiva, devido a sua agressividade. Estas características evidenciam o grande potencial desta espécie para a piscicultura nacional. Entretanto, muitos obstáculos vêm sendo encontrados em relação à criação em larga escala dessa espécie para atender a demanda do mercado consumidor, como dificuldade na aquisição de matrizes de qualidade e no manejo alimentar tanto dos adultos quanto dos alevinos; altos custos de manutenção de reprodutores; falta de estruturas e tecnologia adequada; e pouco conhecimento da biologia dessa espécie.

Para solucionar parte desses obstáculos, visando o desenvolvimento de criação de espécies carnívoras dentro do cenário da aqüicultura nacional, vários pesqui- sadores e empresas têm investido esforços na busca de tecnologia para a produção intensiva desses peixes (Campos, 1998; Machado et al., 1998; Moura, 1998). Segundo Kubitza (1995), técnicas de condicionamento alimentar têm apresentado bons resultados para muitas espécies carnívoras, como a truta arco-íris (Oncorhynchus maximus), o salmão do Atlântico (Salmo salar), largemouth bass (Micropterus salmoides), seabass (Dicentrarchus labrax), entre outras.

Com relação às espécies nativas, o surubim pintado (Pseudoplatystoma corruscans) e o surubim cachara ( $P$. fasciatum) vêm sendo obtidos em cativeiro pela técnica de condicionamento alimentar, proporcionando a produção em larga escala de alevinos com a utilização de rações comerciais, com bons índices de conversão alimentar e altas taxas de crescimento em cultivos semi-intensivo e intensivos (Campos, 1998).

Dessa forma, o presente trabalho foi conduzido com o objetivo de avaliar o condicionamento alimentar de alevinos de trairão (Hoplias cf. Lacerdae).

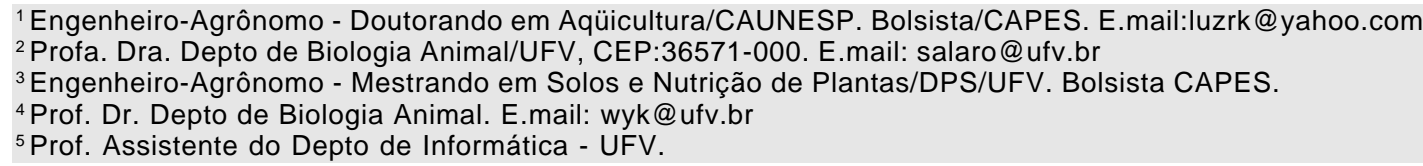




\section{Material e Métodos}

O experimento foi realizado no Laboratório de Nutrição de Peixes do Departamento de Zootecnia da Universidade Federal de Viçosa - UFV - Viçosa - MG, por um período de 17 dias.

Foi utilizado um lote homogêneo de alevinos de trairão (Hoplias cf. lacerdae), provenientes da Estação de Hidrobiologia e Piscicultura do Departamento de Biologia Animal - UFV, com média do comprimento total de $2,9 \pm 0,2 \mathrm{~cm}$ e peso total de $0,42 \pm 0,12 \mathrm{~g}$, oriundos de tanques de criação e submetidos à alimentação natural.

Os alevinos foram acondicionados em uma densidade de 4 animais/L, distribuídos em seis aquários com capacidade para 20 litros, com aeração constante por meio de compressor de ar, pedra porosa e temperatura controlada $\left(27 \pm 0,5^{\circ} \mathrm{C}\right)$.

$\mathrm{O}$ delineamento experimental constou de dois tratamentos com três repetições cada. Nos oito primeiros dias de experimento, os alevinos do tratamento 1 receberam ração comercial extrusada com $42 \%$ de PB, a qual foi farelada manualmente e passada em peneira de $0,5 \mathrm{~mm}$ de malha. A partir do oitavo dia, a ração extrusada foi submetida a um triturador manual para se obterem péletes com diâmetro maior que $0,5 \mathrm{~mm}$.
Os alevinos do tratamento 2 foram submetidos ao condicionamento alimentar, que constitui na substituição parcial e progressiva da dieta semi-úmida por ração seca.

A dieta semi-úmida foi processada, diariamente, misturando-se ração comercial farelada (diâmetro menor que $0,5 \mathrm{~mm}$ ) e coração de boi moído de forma a se obter uma massa consistente e homogênea, sendo os péletes confeccionados manualmente (diâmetro maior que $0,5 \mathrm{~mm}$ ).

As porcentagens das misturas (ração + coração) utilizadas no condicionamento alimentar e os dias de administração das mesmas constam na Tabela $1 \mathrm{e}$ seguem metodologia semelhante à descrita por Kubitza \& Lovshin (1997).

O manejo alimentar foi realizado nos seguintes horários: 8, 10, 14 e 17h. Para os animais submetidos ao tratamento 1 , a ração farelada e triturada foi fornecida de modo a cobrir toda a superfície de água dos aquários. Para o tratamento 2 (coração de boi + ração farelada), foram fornecidos de 2 a 3 péletes/ alevino/alimentação. Os animais dos tratamentos 1 e 2 receberam quantidades equivalentes de alimento.

Antes de cada alimentação, foram quantificados os alevinos mortos e as sobras de ração. Em seguida, foi realizada a limpeza dos aquários retirando-se cerca de $1 / 4$ do volume total, o qual era reposto imediatamente.

Tabela 1 - Composição das rações e duração das fases do condicionamento alimentar dos alevinos de trairão, Hoplias lacerdae

Table 1 - Composition of diets and length of training strategies phases of trairao fingerlings

\begin{tabular}{|c|c|c|c|}
\hline $\begin{array}{l}\text { Ração } \\
\text { Diet }\end{array}$ & $\begin{array}{r}\text { Composição } \\
\text { Composition } \\
\end{array}$ & $\begin{array}{l}\% \text { PB das rações } \\
\text { \% dietary } C P\end{array}$ & $\begin{array}{c}\text { Alimentação (dias) } \\
\text { Feeding (days) }\end{array}$ \\
\hline 1 & $\begin{array}{l}20 \% \text { ração seca }+80 \% \text { coração de } \text { boi }^{2} \\
20 \% \text { dry pellets }+80 \% \text { ox heart }\end{array}$ & 49,13 & 3,5 \\
\hline 2 & $\begin{array}{l}40 \% \text { ração seca }+60 \% \text { coração de boi } \\
40 \% \text { dry pellets }+60 \% \text { ox heart }\end{array}$ & 47,35 & 3,0 \\
\hline 3 & $\begin{array}{l}60 \% \text { ração seca }+40 \% \text { coração de boi } \\
60 \% \text { dry pellets }+40 \% \text { ox heart }\end{array}$ & 45,56 & 3,0 \\
\hline 4 & $\begin{array}{l}80 \% \text { ração seca }+20 \% \text { coração de boi } \\
\quad 80 \% \text { dry pellets }+20 \% \text { ox heart }\end{array}$ & 43,78 & 3,0 \\
\hline 5 & $\begin{array}{c}100 \% \text { ração comercial }(42 \% \mathrm{~PB})^{3} \\
100 \% \text { commercial diet }(42 \% \mathrm{CP})\end{array}$ & 42,00 & 4,0 \\
\hline
\end{tabular}

\footnotetext{
1 Proteína bruta calculada (Calculated crude protein).

${ }^{2}$ Coração de boi (ox heart), \% na MS (\% dry matter): proteína bruta (crude protein) 71,00; extrato etéreo (ether extract) 30,03; matéria fibrosa (fiber matter) 0,00; umidade (moisture) 28,27; cinza (ash) 0,96; energia bruta (gross energy) $5938 \mathrm{kcal} / \mathrm{kg}$. Metodologia para análise (methods of analysis) - AOAC.

${ }^{3}$ Ração comercial (commercial diet): Vitaminas (vitamins): $A=18.000 \mathrm{Ul} ; \mathrm{B}_{1}=156,00 \mathrm{mg} ; \mathrm{B}_{12}=0,06 \mathrm{mcg} ; \mathrm{B}_{3}=30,00 \mathrm{mg} ; \mathrm{B}_{6}=15,00 \mathrm{mg}$; $C=300,00 \mathrm{mg} ; D_{3}=3.000 \mathrm{Ul} ; \mathrm{E}=75,00 \mathrm{mg} ; \mathrm{K}_{3}=7,50 \mathrm{mg}$; ác. fólico (folic acid) 6,00 mg; antioxidante (antioxidant) 185,00 mg; colina (choline) 1.000,00 mg; $\mathrm{Cu}=6,00 \mathrm{mg} ; \mathrm{Co}=0,30 \mathrm{mg} ; \mathrm{Fe}=75,00 \mathrm{mg} ; \mathrm{I}=2,00 \mathrm{mg} ; \mathrm{Mn}=30,00 \mathrm{mg} ; \mathrm{Se}=0,16 \mathrm{mg} ; \mathrm{Zn}=90,00 \mathrm{mg} ; \mathrm{niacina}$ (niacin) $150,00 \mathrm{mg}$.

Níveis de garantia (Guarantee levels) \%: proteína bruta (crude protein) 42,00; extrato etéreo (ether extract) (min) 7,00; matéria fibrosa (fiber matter) (max) 5,00; matéria mineral (mineral matter) (max) 15,00; cálcio (calcium) (max) 4,00; fósforo (phosphorus) (min) 1,50.
}

R. Bras. Zootec., v.31, n.5, p.1881-1885, 2002 
Ao final de cada dia, foi realizada a renovação de $100 \%$ do volume total dos aquários. Realizou-se análise do conteúdo estomacal nos alevinos mortos.

Os aquários foram totalmente cobertos por lona preta, mantendo o ambiente interno escuro, sendo descobertos somente no momento da alimentação, da observação do comportamento dos indivíduos em relação ao alimento fornecido e da limpeza dos mesmos. Estes procedimentos duravam cerca de 15 minutos para cada aquário.

Adotou-se o regime de escuridão total (fotoperíodo de 0L:24E), pois, em observações preliminares, notou-se que, na presença de luz, os animais se aglomeravam no fundo dos aquários, aumentando o contato entre os peixes e possibilitando, assim, a ocorrência de canibalismo.

Ao final do experimento, foram analisadas as taxas de sobrevivência, mortalidade e canibalismo, além do peso total e comprimento total. Para as medidas de peso, os alevinos foram coletados com peneira e colocados sobre uma toalha para a retirada do excesso de umidade. Posteriormente, foram pesados em balança analítica com precisão de 0,01 g. Para o comprimento total, foram realizadas medidas da parte anterior da cabeça ao final da nadadeira caudal, com o auxílio de paquímetro. Os dados foram analisados aplicando-se o teste $t$.

A taxa de canibalismo foi calculada utilizando-se a fórmula: Taxa de Canibalismo = (número de alevinos iniciais - número de alevinos vivos - número de alevinos mortos/número de alevinos iniciais) x 100 .

\section{Resultados e Discussão}

No primeiro tratamento, em que os peixes foram submetidos ao arraçoamento a seco, ou seja, transição súbita do alimento natural pela dieta artificial, observou-se alevinos de trairão ingerindo a ração apenas no sétimo dia do experimento. A partir do nono dia, iniciou-se a mortalidade de animais. A taxa de mortalidade ao final do experimento foi de $65,83 \%$ (Tabela 2). Provavelmente, o alto índice de mortalidade evidencia a não aceitação da ração comercial extrusada pelos alevinos, quando oferecida sem um condicionamento prévio, uma vez que, durante a análise do conteúdo estomacal, não foi detectada a presença de ração no estômago desses peixes.

Segundo Kubitza (1995), a transição súbita é um método que não leva em consideração as diferenças existentes entre o alimento natural e a ração, não sendo, portanto, adequada para que animais carnívoros passem a aceitar alimento inerte.

Com relação aos alevinos submetidos ao condicionamento alimentar, segundo tratamento, verificou-se que os peixes iam em direção ao alimento fornecido e mordiam os péletes já no primeiro dia de alimentação. No quinto dia de experimento, observou-se que, pela primeira vez, alevinos de trairão ingeriam péletes inteiros. Alguns peixes passaram a atacar a ração antes mesmo que esta chegasse ao fundo do aquário, demonstrando boa aceitação do alimento na forma de ração semi-úmida. Portanto, a mistura de coração de boi + ração seca mostrou-se muito eficiente para o treino de alevinos de trairão.

Segundo Kubitza (1995), alguns fatores são fundamentais para o sucesso do condicionamento alimentar, como aspecto atrativo do alimento, textura adequada para a espécie e palatabilidade. Outros ingredientes de origem animal - peixes moídos e subprodutos de peixes e crustáceos - também têm sido utilizados como estimulantes, com sucesso, por diversos autores (Snow, 1963; Nelson et al., 1974; Anderson, 1974; Flickinger et al., 1975; Flickinger \& Smeltzer, 1983; Higgs et al, 1985; Chaitanawisuti \& Menasveta, 1989).

O processo de transição alimentar da ração semiúmida para ração seca tem se mostrado eficaz no condicionamento de espécies carnívoras (Anderson, 1974; Flickinger et al., 1975; Williis \& Flickinger, 1981, 1982; Lovshin \& Rushing, 1989).

Fernández-Días et al. (1994), para pós-larvas de "sea bream", relataram melhor aceitação de rações artificiais, quando foram fornecidos alimentos vivos (náuplios de Artemia) juntamente com a ração. Kubitza \& Lovshin (1997), trabalhando com "largemouth bass", afirmaram que o "krill" seco congelado é um dos melhores atrativos alimentares para ser usado no início de dietas de treino alimentar.

$\mathrm{Na}$ última fase de condicionamento alimentar deste trabalho, quando os alevinos passaram a receber apenas a ração comercial, observou-se a ingestão dos péletes imediatamente após seu fornecimento.

Ao final do experimento (16,5 dias), obtiveram-se taxas médias de sobrevivência de 27,50 e $96,66 \%$, respectivamente, para os tratamentos com transição súbita do alimento natural pela dieta artificial e com o condicionamento alimentar (Tabela 2). Observações semelhantes foram relatadas por Kubitza \& Lovshin (1997), para o largemouth bass (Micropterus salmoides), com aceitação de ração artificial por $65 \%$

\section{R. Bras. Zootec., v.31, n.5, p.1881-1885, 2002}


Tabela 2 - Valores da média de porcentagem de sobrevivência, mortalidade, canibalismo, peso final e do comprimento final dos alevinos de trairão (Hoplias cf. lacerade) submetidos aos diferentes tratamentos alimentares

Table 2 - Average values (\%) of survival, mortality, canibalismm, final weight and final lenght of trairao (Hoplias cf.lacerade) fingerlings under different feeding treatments

\begin{tabular}{|c|c|c|c|}
\hline \multirow[t]{2}{*}{$\begin{array}{l}\text { Valores médios } \\
\text { Average values }\end{array}$} & \multicolumn{3}{|c|}{$\begin{array}{l}\text { Tratamento } \\
\text { Treatment }\end{array}$} \\
\hline & $\begin{array}{l}\text { Dieta artificial } \\
\text { Drypellets }\end{array}$ & $\begin{array}{c}\text { Condicionamento alimentar } \\
\text { Training strategies }\end{array}$ & $\mathrm{CV} \%$ \\
\hline Sobrevivência (\%) & $27,50^{\mathrm{b}}$ & $96,66^{\mathrm{a}}$ & 9,41 \\
\hline Mortalidade (\%) & $65,83^{b}$ & $2,20^{\mathrm{a}}$ & 19,56 \\
\hline Canibalismo (\%) & $6,67^{\mathrm{b}}$ & $1,14^{\mathrm{a}}$ & 98,2 \\
\hline $\begin{array}{l}\text { Canibalismm }(\%) \\
\text { Média de peso final }(\mathrm{g}) \\
\text { Final average weight }(\mathrm{g})\end{array}$ & $0,62 \pm 0,04^{\mathrm{b}}$ & $0,89 \pm 0,03^{\mathrm{a}}$ & 7,30 \\
\hline $\begin{array}{l}\text { Média de comprimento final }(\mathrm{cm}) \\
\text { Final average lenght }(\mathrm{cm})\end{array}$ & $3,78 \pm 0,10^{\mathrm{a}}$ & $4,04 \pm 0,05^{\mathrm{a}}$ & 3,76 \\
\hline
\end{tabular}

dos peixes, quando passaram por condicionamento alimentar prévio, enquanto apenas de 9 a $12 \%$ dos peixes sem condicionamento prévio aprenderam a comer ração, quando esta foi fornecida diretamente.

Os resultados obtidos por Campos (1998) com várias espécies de Pimelodidae submetidas ao condicionamento alimentar foram semelhantes aos observados no presente trabalho, ou seja, 80 a $95 \%$ de sobrevivência ao final de um período de 28 dias. Machado et al. (1998) obtiveram taxa de sobrevivência de 78,4\%, após 84 dias de alimentação de alevinos de pintado (Pseudoplatystoma corruscans), quando utilizaram coração de boi durante a fase de treino. Moura (1988), testando diferentes estratégias de condicionamento alimentar para tucunaré (Cichla sp), obteve sobrevivência média de $11,8 \%$ ao final de 29 dias de experimento, quando utilizou farinha de peixe nos primeiros nove dias e a transição alimentar nos últimos 20 dias. Este mesmo autor, em um segundo trabalho, em que foi oferecida farinha de peixe por três dias e posterior transição alimentar por 16 dias, observou valores médios de sobrevivência de 31,6\%. Estes resultados demostram que peixes carnívoros podem ser condicionados a aceitar dietas artificiais, reduzindo, assim, custos de manejo e produção final.

A utilização de lotes homogêneos de alevinos de trairão com tamanho inicial de 2,9 $\pm 0,2 \mathrm{~cm}$ de comprimento mostrou-se apropriada para a aplicação de estratégias de condicionamento alimentar, proporcionando baixas taxas de canibalismo (Tabela 2). De acordo com Luz et al. (2000), quanto menores as diferenças de tamanho dos alevinos de trairão, menor o canibalismoe, conseqüentemente, maior a taxa de sobrevivência.

Observações preliminares de condicionamento alimentar com exemplares de trairão menores que $1 \mathrm{~cm}$ de comprimento total, em condições de fotoperíodo natural, mostraram taxas de mortalidade e canibalismo bem mais acentuadas, quando comparadas aos exemplares de 2,9 $\pm 0,2 \mathrm{~cm}$ em regime de escuridão total (0L:24D).

O tamanho inicial dos animais parece ser fundamental para o início do condicionamento alimentar. Snow (1960, 1963) observou que alevinos de largemouth bass com $4 \mathrm{~cm}$ de comprimento aceitaram melhor alimentos inertes que alevinos menores. Este fato também foi relatado por Moura (1988), para o tucanaré (Cichla sp). Bromley (1978), realizando a transição do alimento natural para dietas secas, observou que a taxa de sobrevivência aumenta quando as pós-larvas são maiores. Kubitza \& Lovshin(1997b), em trabalhos com largemouth bass, obtiveram maior sucesso com a técnica de treino alimentar entre alevinos de peso inicial de 1,4 g, quando comparados com alevinos de $0,2 \mathrm{~g}$.

A luminosidade também parece ser outro fator importante a ser considerado para a criação de espécies carnívoras em condições de laboratório. Segundo Luz \& Portella (2002), a baixa intensidade luminosa, juntamente com a utilização de náuplios de Artemia 
como alimento para larvas de trairão durante os primeiros 15 dias de alimentação, proporcionou sobrevivência de $100 \%$ dos animais. Valores de sobrevivência superiores a $91 \%$ foram observados por Luz \& Portella (2002), quando submeteram larvas de trairão em regime de escuridão total e diferentes salinidades da água.

O comprimento final dos alevinos para os dois tratamentos foi semelhante, sendo o peso médio final superior para o tratamento em que foi realizado o condicionamento alimentar (Tabela 2), podendo-se inferir que esta prática proporciona alevinos com melhores condições de adaptação a mudanças alimentares.

\section{Conclusões}

O condicionamento alimentaré uma forma eficiente na alimentação artificial de alevinos de trairão.

$\mathrm{O}$ condicionamento alimentar proporcionou alevinos com melhores condições de adaptação e resistência a mudanças alimentares.

\section{Literatura Citada}

ASSOCIATION OF OFFICIAL ANALYTICAL CHEMISTS AOAC. Official methods of analysis. Arlington: AOAC, 1984. $1097 \mathrm{p}$.

ANDERSON, R.J. Feeding artificial diets to smallmouth bass. Progressive Fish-Culturist, v.36, p.145-151, 1974.

BROMLEY, P.J. The weaning of hatchery reared turbot larvae (Scophthalmus maximus L.) on dry diet. Aquaculture, v.12, p.337-347, 1978.

CAMPOS, J.L. Produção intensiva de peixes de couro no Brasil. In: SIMPÓSIO SOBRE MANEJO E NUTRIÇÃO DE PEIXES, 2., 1998, Piracicaba. Anais... Piracicaba: 1998.p.61-72.

CHAITANAWISITU, N.; MENASVETA, P. Effect of pelleted diets containing different moisture content on growth and feed conversion efficiency of juvenile seabass (Lates calcarifer BLOACH). Journal of Aquaculture Tropical, v.4, p.147$155,1989$.

FERNÁNDEZ-DÍAZ, C.; PASCUAL, E.; YÚFERA, M. Feeding behaviour and prey size selection of gilthead sea bream, Sparus aurata, larvae fed on inert and live food. Marine Biology, v.118, p.323-328, 1994

FLICKINGER, S.A.; ANDERSON, R.J.; PUTTMANN, S.J. Intensive culture of smallmouth bass. In: BLACK BASS BIOLOGY MANAGEMENT NATIONAL SYMPOSIUM ON THE BIOLOGY AND MANAGEMENT OF THE CENTRARCHID BASSES. Black bass biology management, 1975. p.373-379.

FLICKINGER, S.A.; SMELTZER, J.F. Training spotted bass to accept a prepared diet. Progressive Fish-Culturist, v.45, p.185-186, 1983.

HIGGS, D.A.; MARKERT, J.R.; PLOTNIKOFF, M.D. et al. Development of nutritional and environmental strategies for maximizing the growth and survival of juvenile pink salmon (Oncorhynchus gorbuscha). Aquaculture, v.47, p.113-130, 1985.
KUBITZA, F. Preparo de rações e estratégias de alimentação no cultivo intensivo de peixes carnívoros. In: SIMPÓSIO INTERNACIONAL SOBRE NUTRIÇÃO DE PEIXES E CRUSTÁCEOS, 1995, Campos do Jordão. Anais... Campos do Jordão: 1995. p.91-109.

KUBITZA, F.; LOVSHIN, L.L. The use of freeze-dried krill to feed train largemouth bass (Micropterus salmoides): feeds and training strategies. Aquaculture, v.148, p.299-312, 1997a.

KUBITZA, F.; LOVSHIN, L.L. Effects of initial weight and genetic strain on feed training largemouth bass Micropterus salmoides using ground fish flesh and freeze dried krill as starter diets. Aquaculture, v.148, p.179-190, $1997 \mathrm{~b}$.

LOVSHIN, L.L.; RUSHING, J.H. Acceptance by largemouth bass fingerlings of pelleted feeds with a gustatory additive. Progressive Fish-Culturist, v.51, p.73-78, 1989.

LUZ, R.K.; PORTELLA, M.C. Larvicultura de trairão (Hoplias lacerdae ) em água doce e água salinizada. Revista Brasileira de Zootecnia, v.31, n.2, p.829-834, 2002. (suplemento)

LUZ, R.K.; PORTELLA, M.C. Utilização de alimento vivo e alimento inerte na larvicultura de trairão Hoplias lacerdae. In: CONGRESSO BRASILEIRO DE ZOOLOGIA, 24., 2002, Itajaí. Resumos... Itajaí, SC, 2002. CD Rom.

LUZ, R.K.; SALARO, A.L.; SOUTO, E.F. et al. Avaliação de canibalismo e comportamento territorial de alevinos de trairão (Hoplias lacerdae). Acta Scientiarum, v.22, n.2, p.465-469, 2000.

MACHADO, J.H.; DEL CARRATORE, C.R.; GAROSSINO, A.P.R. et al. Treinamento alimentar para aceitação de rações artificiais por alevinos de pintado(Pseudoplatystoma corruscans). In: SIMPÓSIO BRASILEIRO DE AQUICULTURA, 10., 1998, Recife. Anais... Recife: 1998. p.101-108.

MOURA, M.A.M. Estratégias de condicionamento alimentar do tucunaré (Cichla $\mathbf{s p )}$ ). Piracicaba: Escola Superior de Agricultura "Luiz de Queiroz", 1998. 43p. Dissertação (Mestrado em Agronomia) - Escola Superior de Agricultura "Luiz de Queiroz", 1998.

NELSON, J.T.; BOWKER, R.G.; ROBINSON, J.D. Rearing pellet-feed largemouth bass in a raceway. Progressive FishCulturist, v.36, p.108-110, 1974

SNOW, J.R. Na exploratory attempet to rear largemouth black bass fingerlings in a controlled environment. In: ANNUAL MEETING OF THE SOUHTEASTERN ASSOCIATION OF GAME AND FISHCOMMISSIONERS, 14., 1960, Bioloxi, Mississipi. Proccedings... Bioloxi, Mississipi, 1960. p.191-203.

SNOW, J.R. Results of further experiments on rearing largemouth bass fingerlings under controlled conditions. In: ANNUAL MEETING OF THE SOUHTEASTERN ASSOCIATION OF GAME AND FISH COMMISSIONERS, 1963, 17., Arkansas. Proceedings... Hot Springs, Arkansas: 1963. p.191-203.

WILLIS, D.W.; FLICKINGER, S.A. Intensive culture of largemouth bass fry. Transaction of the American Society of Agricultural Engineering, v.110, p.650-655, 1981.

WILLIS, D.W.; FLICKINGER, S.A. Common carp eggs as a starter diets for the intensive culture of smallmouth bass fry. Progressive Fish-Culturist, v.44, p.28-29, 1982.

Recebido em: $16 / 11 / 00$ Aceito em: 28/05/02 